\title{
Running Head: Context-Specific Recall of Self-Cognitions: Language as a Prime for Positive Relational Self-Statements
}

\author{
Gregg D. Bromgard ${ }^{1}$, David Trafimow ${ }^{2}$, Christopher D. Linn ${ }^{3}$ \\ ${ }^{1}$ Southern University at New Orleans, ${ }^{2}$ New Mexico State University, ${ }^{3}$ Southern University at New Orleans
} Abstract: Three types of self-cognitions are hypothesized: (a) private self-cognitions; (b) collective self-
cognitions, and (c) relational self-cognitions. Trafimow, Triandis, and Goto (1997) showed that language affects
the activation the private and collective self. However, they did not investigate how language affects their
valences. There is reason to believe that language should have differential effects on the valences of private,
collective, and relational self-cognitions. Because private and collective self-cognitions tend to be abstract, they
are generally good or bad regardless of context. In contrast, relational self-cognitions are more specific and have
valences that are more strongly linked to specific contexts. Consequently, their valences are more amenable to
being influenced by a language manipulation. We found evidence of this in the present experiment

\section{INTRODUCTION}

Previous research has conceptualized the self as two distinct concepts; the private and collect self (Greenwald \& Pratkanis, 1984; Triandis, 1989). The private self includes cognitions involving traits, states or behaviors. For example, the self-statement "I am honest" is a private self-cognition. The collective self involves cognitions about group membership. For example, "I am on a baseball team" is a collective self-cognition.

Trafimow, Triandis, and Goto (1991) demonstrated that both private and collective self-cognitions are stored in two separate areas in memory. They demonstrated that if a person retrieved a private self-cognition, it was much more likely that the person's next self-cognition would be another private self-cognition. On the other hand, if a person retrieved a collectivistic self-cognition, it was much more likely that the person's next self-cognition would be another collective self-cognition. They also demonstrated that priming a particular aspect of the self increased the recall of self-cognitions pertaining to that aspect of the self. This research is consistent with the notion of two separate structures where self-cognitions are organized and stored.

It has also been hypothesized that individuals have a relational self where relational self-cognitions are stored (Brewer \& Gardner, 1996; Triandis, Chan, Bhawuk, Iwao, \& Sinha, 1995). Cross and Madson (1997) stressed that males and females differ in the structure of the self; that females were more relational (or allocentric) than males. Gabriel and Gardner (1999) illustrated that both males and females have a relational self; females had more dyadic relational self-cognitions, whereas males had more group relational cognitions. In addition, Madson and Trafimow (2001) demonstrated that females described themselves with more relational (allocentric) cognitions than did males. These previous experiments suggest the existence of a separate structure where relational self-cognitions are stored.

\section{Abstract Private And Collective Self-Cognitions}

Private and collective self-cognitions are abstract in nature and are relatively stable. For example, suppose one thinks that he or she is an honest person (a private self-cognition) or a member of a baseball team (a collective selfcognition). Context will have little effect on the valence of these self-cognitions. The context, whether it is general or specific, does not influence the positivity or negativity of the self-cognitions of being honest or a member of a baseball team. Therefore, private and collective self-cognitions are abstract and are stable.

Now consider self-cognitions that refer to the relational self. These self-cognitions are less abstract and are less stable. For example, suppose one produces a relational self-cognition that he is a father. In a general sense, this is always a positive thing - being a father is good. However, when context matters, then one could think of himself as a good father because they help provide money for his children or one can think of himself as a bad father because he does not spend enough time with his son. Therefore, relational self-cognitions are less abstract and are less stable than private or collective self-cognitions.

III. Language As A Prime

${ }^{1}$ Corresponding Author: GBromgard@suno.edu 
Trafimow and colleagues (1997) demonstrated that language could activate the private or collective self. They claim that "language cues" in memory get activated when speaking one's native language along with a private self and a collective self that develop in the context of the activation of such cues. Trafimow et. al. continue by saying:

...it follows that activated language cues will occur in temporal contiguity with the activation of the private self at times and with the activation of the collective self at other times. During these moments of temporal contiguity, associations between the language cues and the activated self-concept can form; as there are more such instances of temporal contiguity, the association gets stronger. (p.110)

They demonstrated that Chinese participants who received instructions in their native language recalled more collectivistic self-statements than when they received instructions in English. This is consistent with the notion that self-concepts develop in temporal contiguity with language (China is considered a collectivistic culture).

\section{THE CURRENT RESEARCH}

Trafimow et. al. (1997) showed that language affects the activation of self-cognitions. However, they did not investigate how language affects their valences. There is reason to believe that language should have differential effects on the valences of private, collective, and relational self-cognitions. Because private and collective selfcognitions tend to be abstract, they are generally good or bad regardless of context. In contrast, relational selfcognitions are more specific and have valences that are more strongly linked to specific contexts. Consequently, their valences are more amenable to being influenced by a language manipulation. We tested this in the present experiment.

\section{METHODS}

\subsection{Participants}

Thirty-six Chinese students from a university in Hong Kong participated for course credit. Fifty-eight percent of the participants self-identified as being male, whereas thirty-three percent self-identified as being female. All participants were above the age of eighteen and were randomly assigned to conditions.

\subsection{Materials and Procedure}

Participants were presented with the Kuhn and McPartland (1954) self-attitude instrument (i.e., 20 sentences beginning with "I am") in English or Chinese. Demographics were also collected at the end of the survey. Three experimental volunteers, who were blind to the experiment, coded the twenty self-statements. Each statement was coded for valence (positive, neutral, and negative) and self-statement type (individual, collective, and relational).

\section{RESULTS}

The self-statements were coded and converted to proportions. The neutral and negative self-statements were collapsed to create a polarized positive-not positive dichotomy. Although no main effects were found for language or valence on self-statement type, we did obtained a significant interaction for language and valence on selfstatement type, $F(1,9)=9.68, \mathrm{p}<.05$. Participants who received the instructions in their second language recalled more positive relational self-statements than did participants who received the instructions in their native language (see Table 1).

Table1. Proportions of Positive and Not-Positive Self-Statements

\begin{tabular}{|l|l|l|l|l|l|l|}
\hline & \multicolumn{2}{|l|}{} & Self-Statement Type & \multicolumn{2}{l|}{} \\
\hline & & & Collective & Individualistic & Relational \\
\hline & & Valence & & & \\
\hline & English & Positive & .04 & .44 & $1.00^{*}$ \\
\hline & & Not-Positive & .96 & & .56 & $.00^{*}$ \\
\hline Language & & & & & \\
\hline & & Valence & .07 & .31 & \\
\hline & Chinese & Positive & .07 & .69 & $.49^{*}$ \\
\hline & & Not-Positive & .93 & & $.51^{*}$ \\
\hline
\end{tabular}

\section{DISCUSSION}




\section{American Research Journal of History and Culture, Volume 1, Issue 1, February 2015 \\ ISSN 2379-2914}

Our study showed that language has differential effects on the valences of private, collective, and relational selfcognitions. Thus, activating the private self in collectivistic cultures resulted in more positive relational statements. Private and collective self-cognitions as a whole tend to be abstract and therefore generally good or bad regardless of context. In contrast, relational self-cognitions are more specific and have valences that are more strongly linked to specific contexts. Consequently, their valences were more amenable to being influenced by the language manipulation. To our knowledge the present experiment is the first demonstration that language affects the valence of relational self-cognitions.

\section{REFERENCES}

[1] Hofstede, G. (1980). Culture's consequences. Beverely Hills, CA: Sage

[2] Hsu, F. L. K. (1981). American and Chinese: Passage to differences. Honolulu: University of Hawaii Press.

[3] Hsu, F. L. K. (1983). Rugged individualism reconsidered. Knoxville: University of Tennessee Press.

[4] Hsu, F. L. K. (1985). The self in cross-cultural prespective. In A. J. Marsella, G. DeVos, \& F.L.K. Hsu (Eds.), Cultural and self (pp. 24-55). London: Tavistock.

[5] Kuhn, M. H., \& McPartland, T. (1954). An empirical investigation of self-attitudes. American Sociological Review, 19, 5876.

[6] Singelis, T. M. (1994). The measurement of independent and interdependent self-construals. Personality-and-SocialPsychology Bulletin, 20, 580-591.

[7] Triandis, H. C. (1989). The self and social behavior in differing cultural contexts. Psychological Review, 96, 506-520.

[8] Trafimow, D., Brown, J., Cone, J., Johns, E., \& Madson, L (under review). The Importance and Cognitive Centrality of the Relational Self. Unpublished manuscript.

[9] Trafimow, D., Silverman, E. S., Mei-Tai Fan, R., \& Shui Fun Law, J. (1997). The effects of language priming on the relative accessibility of the private self and the collective self. Journal of Cross-Cultural Psychology, 28, 107-123.

[10] Trafimow, D., Triandis, H. C., \& Goto, S. G. (1991). Some tests of the distinction between the private self and the collective self. Journal of Personality and Social Psychology, 60, 649-655. 